\title{
ANALISIS PEMINATAN STAKEHOLDER TERHADAP EFEKTIVITAS PEMANFAATAN TERMINAL PENUMPANG DI KABUPATEN PANGKEP (Studi Kasus Terminal Penumpang Pangkajene Kab. Pangkep)
}

\author{
St Maryam $\mathrm{H}^{1}$, Lambang Basri Said ${ }^{2}$, Irfan Nurdin ${ }^{3}$ \\ ${ }^{1}$ Dosen Jurusan Teknik Sipil Universitas Muslim Indonesia (UMI) \\ Jalan Urip Sumoharjo No.225 Makassar, Telp. 454534 \\ ${ }^{2}$ Dosen Jurusan Teknik Sipil Universitas Muslim Indonesia (UMI) \\ Jalan Urip Sumoharjo No.225 Makassar, Telp. 454534 \\ ${ }^{3}$ Mahasiswa Magister Teknik Sipil Universitas Muslim Indonesia (UMI) \\ Jalan Urip Sumoharjo No.225 Makassar, Telp. 454534, Email : nurdin irfan@yahoo.com
}

\begin{abstract}
Abstrak
Kendaraan angkutan umum tidak lagi memasuki dan parkir dalam terminal bungoro untuk menaikkan dan/atau menurunkan penumpang akantetapi berada di pinggir-pinggir jalan arteri dan menciptakan terminal bayangan seperti terlihat di jalan poros Makassar-Pare Pare tepatnya di depan Rumah Sakit Batara Siang Kab. Pangkep, Depan Kantor BRI Cabang Pangkep, Persimpangan Empat Bungoro dan di Jalan Sultan Hasanuddin.Pangkep serta di beberapa titik ruas sepanjang jalan Poros Makassar Pare-pare. Belum efektifnya pemanfaatan Terminal Penumpang yang telah dibangun membuat perkembangan aktivitas dan kegiatan di dalam dan di sekitar terminal tidak berjalan dengan baik, sepinya aktivitas dalam terminal ini membuat bangunan-bangunan seperti kios, halte dan beberapa fasilitas lainnya terbengkalai, tidak terurus dan sudah dalam kondisi rusak. Tujuan dari peneilitian ini adalah (1) Untuk menganalisis peminatan stakeholder terhadap efektivitas pemanfaatan terminal penumpang di Kabupaten Pangkep, dan (2) Merumuskan alternatif arahan efektivitas pemanfaatan terminal penumpang di Kabupaten Pangkep. kerangka pemikiran yang mendasari penelitian ini adalah menganalisis peminatan stakeholder terhadap efektivitas pemanfaatan terminal penumpang serta merumuskan alternative arahan efektivitas pemanfaatan terminal penumpang di Kabupaten Pangkep tersebut dengan memperhatikan kondisi eksisting dan persepsi peminatan stakeholder terhadap efektivitas pemanfaatan terminal. Hasil penelitian menunjukkan bahwa (1) Dari 310 jumlah responden yang terdiri dari 15 orang responden regulator (pemerintah), 122 orang responden operator (sopir) dan 173 orang responden user (penumpang) maka diperoleh bahwa fasilitas dan manajemen terminal memiliki tingkat peminatan responden yang paling tinggi sebanyak 148 orang dengan prosentase bobot sebesar 39,97\%, kemudian aksesibilitas sebanyak 134 orang dengan prosentase bobot sebesar 33,06\%, keamanan terminal sebanyak 21 orang dengan prosentase bobot sebesar 15,55\% dan kenyamanan terminal sebanyak 7 orang dengan memiliki prosentase bobot paling rendah yakni sebesar $11,42 \%$. Dan (2) peminatan stakeholder dan hasil observasi kondisi eksisting terminal penumpang di Kabupaten Pangkep, maka dirumuskan alternatif arahan dalam rangka efektivitas pemanfaatan terminal yaitu perlunya pemenuhan penyediaan fasilitas, termasuk melakukan perbaikan terhadap fasilitas yang telah rusak sehingga dapat difungsikan. Disamping itu perlunya menciptakan sistem kegiatan dalam terminal seperti pemanfaatan kioskios, mengarahkan pengembangan pusat kegiatan baik kegiatan wilayah maupun lokal di dalam dan/atau sekitar terminal tepatnya jalan terminal baru seperti kegiatan pusat kuliner, bandeng tanpa duri (batari) dan lain-lain yang dapat menarik dan membangkitkan orang mengakses terminal baik bagi penumpang angkutan umum (user) maupun masyarakat umum, serta perlu regulasi dan dokumen perencanaan yang mengatur sistem jaringan trayek yang jelas seperti dokumen tatanan transportasi lokal (tatralok).
\end{abstract}

Kata Kunci : Terminal Bungoro, TATRALOK, Efektifitas, pemanfaatan. 


\section{PENDAHULUAN}

\subsection{Latar Belakang}

Terminal penumpang bungoro yang masyarakat luas mengenal dengan sebutan Terminal Bungoro terletak di Kelurahan Samalewa Kecamatan Bungoro Kabupaten Pangkajene dan Kepulauan merupakan terminal Penumpang tipe C (SK Bupati Pangkajene dan Kepulauan Nomor 813 Tahun 2018 tentang Penetapan Terminal Bungoro sebagai Terminal Penumpang Tipe C) yang secara geografis sebagai simpul jaringan transportasi di Kabupaten Pangkajene dan Kepulauan khususnya wilayah kecamatan di daratan, seyogyanya harus efektif agar dapat memenuhi tuntutan pelayanan seoptimal mungkin sehingga dapat memberikan dan meningkatkan pelayanan disektor perhubungan baik dari aspek aksesibilitas moda transportasi, maupun dalam penertiban lalu lintas. Namun pada kenyataannya, Terminal Bungoro yang berubah nama menjadi Terminal Pangkajene tersebut nampaknya belum efektif dan belum sesuai dengan fungsi terminal semestinya. Kendaraan angkutan umum tidak lagi memasuki dan parkir dalam terminal untuk menaikkan dan/atau menurunkan penumpang akantetapi berada di pinggir-pinggir jalan arteri dan menciptakan terminal bayangan seperti terlihat di jalan poros Makassar-Pare Pare tepatnya di depan Rumah Sakit Batara Siang Kab. Pangkep, Depan Kantor BRI Cabang Pangkep, Persimpangan Empat Bungoro dan di Jalan Sultan Hasanuddin.Pangkep serta di beberapa titik ruas sepanjang jalan Poros Makassar Pare-pare.

Belum efektifnya pemanfaatan Terminal Penumpang yang telah dibangun membuat perkembangan aktivitas dan kegiatan di dalam dan di sekitar terminal tidak berjalan dengan baik, sepinya aktivitas dalam terminal ini membuat bangunan-bangunan seperti kios, halte dan beberapa fasilitas lainnya terbengkalai, tidak terurus dan sudah dalam kondisi rusak.

\subsection{Rumusan Masalah}

Dengan meninjau uraian latar belakang di atas, maka permasalahan dari penulisan tesis ini adalah:

1. Sejauh mana peminatan stakeholder terhadap efektivitas pemanfaatan terminal penumpang di Kabupaten Pangkep tersebut.

2. Bagaimana alternaitf arahan efektivitas pemanfaatan terminal penumpang di Kabupaten Pangkep

\subsection{Tujuan Penelitian}

Tujuan dari peneilitian ini adalah:

1. Untuk menganalisis peminatan stakeholder terhadap efektivitas pemanfaatan terminal penumpang di Kabupaten Pangkep

2. Merumuskan alternatif arahan efektivitas pemanfaatan terminal penumpang di Kabupaten Pangkep

\section{METODOLOGI PENELITIAN}

\subsection{Pendekatan Penelitian}

Menurut Ishikawa (1987) dalam Maulana (2000) cara menemukan permasalahan atau penyimpangan dalam penyelenggaraan suatu kegiatan untuk pencapaian mutu

1. Berdasarkan penyebab, identifikasi permasalahan dengan cara membandingkan seluruh kondisi yang ada dengan standar yang ditetapkan. Penyebab yang memberikan pengaruh cukup besar mendapat prioritas untuk ditangani terlebih dahulu, pemeriksaan bertujuan memastikan apakah semua faktor penyebab tersebut dibawah standar yang ditentukan. 
2. Identifikasi berdasarkan akibat yang dilakukan dengan mengamati berbagai akibat yang ditimbulkan dari penyelenggaraan. Akibat yang tidak sesuai dengan standar merupakan adanya ketidak sesuaian dengan metode yang telah ditetapkan dalam pelaksanaannya. Akibat ketidak sesuaian tersebut biasanya menyangkut dana yang terbatas.

Penggabungan kedua cara diatas dapat memberikan gambaran yang menyeluruh dan dapat memberikan informasi secara lengkap. Selain itu tinjauan antara penyebab dan akibat dapat mempermudah penyusunan langkah perbaikan yang tepat.

Berdasarkan latar belakang penelitian, permasalahan, tujuan serta tinjauan pustaka, maka kerangka pemikiran yang mendasari penelitian ini adalah menganalisis peminatan stakeholder terhadap efektivitas pemanfaatan terminal penumpang serta merumuskan alternative arahan efektivitas pemanfaatan terminal penumpang di Kabupaten Pangkep tersebut dengan memperhatikan kondisi eksisting dan persepsi peminatan stakeholder terhadap efektivitas pemanfaatan terminal.

Penelitian ini diawali dengan pengumpulan data dan informasi dalam rangka identifikasi beberapa masalah dan kondisi efektivitas pemanfaatan terminal penumpang di Kabupaten Pangkajene dan Kepulauan. Identifikasi tersebut dilakukan melalui survey langsung di lapangan, wawancara tak terstruktur terhadap orang yang memahami atau turut merasakan kondisi. Oleh karena itu, wawancara dilakukan terhadap regulator (Bappeda, Litbangda, dan Dinas Perhubungan), Sopir dan Penumpang, yang selanjutnya dilakukan identifikasi tingkat peminatan oleh para stakeholder (Pemerintah, Sopir dan Penumpang) terhadap faktor-faktor efektivitas pemanfaatan terminal dengan menggunakan metode kuantitatif dengan teknik Analisis Hirarki Proses (AHP) perbandingan berpasangan sehingga diperoleh nantinya bobot prioritas untuk setiap kriteria/faktor-faktor efektivitas tersebut.

Untuk alternatif arahan efektivitas pemanfaatan terminal penumpang menggunakan metode kualitatif deskriktif dengan melakukan analisis terhadap faktor efektivitas, tingkat peminatan pengguna dan pemberi layanan, serta kondisi terhadap faktor-faktor tersebut yang meliputi:

a) Kondisi internal seperti fasilitas dan manajemen terminal, kondisi keamanan dan kenyamanan internal terminal, dengan membandingkan antara kondisi di lapangan dengan kondisi yang seharusnya sebagaimana diatur dalam Peraturan Menteri Perhubungan RI Nomor PM 40 Tahun 2015 tentang Standar Pelayanan Penyelenggaraan Terminal Penumpang Angkutan Jalan.

b) Kondisi eksternal seperti aksesibilitas yang meliputi system jaringan prasarana jalan, sistem jaringan trayek meliputi sistem pergerakan, kelembagaan, dan sistem kegiatan.

\subsection{Tahapan Analisis}

Metode dan Analisis yang digunakan dalam penelitian ini adalah metode gabungan antara kualitatif dan kuantitatif dengan teknik analisis data menggunakan Analisis Hirarki Proses (AHP) perbandingan berpasang-pasangan.

Dalam melakukan Analisis Hirarki Proses (AHP), terlebih dahulu dilakukan identifikasi masalah, kemudian mengurai masalah tersebut kedalam hirarkinya (dekomposisi masalah), dengan tingkatan tujuan, kriteria/pilihan seperti gambar skema 3.5. berikut:

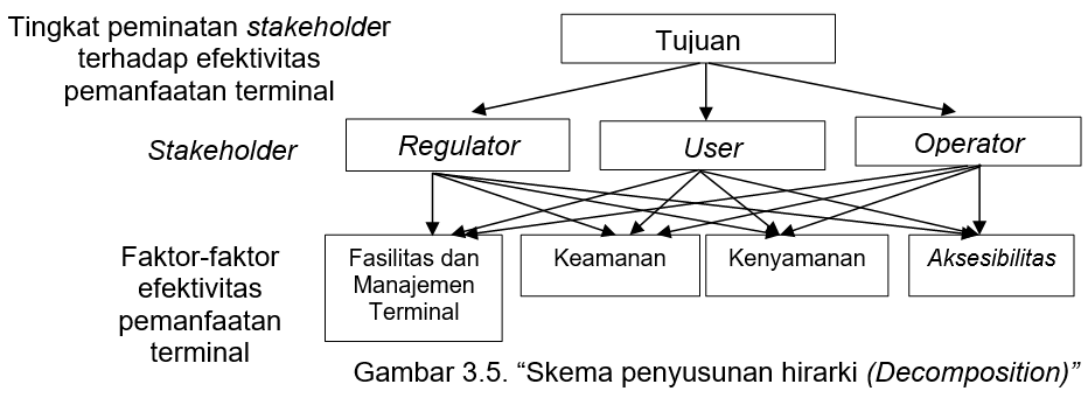




\section{ANALISIS DATA}

\section{Alternatif Arahan Efektivitas Pemanfaatan Terminal.}

Efektivitas merupakan pencerminan hubungan antara fasilitas yang telah disediakan dan manfaat yang dicapai dari penyediaan fasilitas tersebut. dimana keluaran akhir dari penyediaan fasilitas dari suatu lokasi pelayanan umum mempunyai arah tujuan kedalam suatu sistem sehingga efektivitas berdasarkan tujuan dalam sistem pelayanan umum dapat dianalisa dengan kerangka yang jelas, terstruktur dan sistematis.

Pengertian ini bermakna bahwa konsep efektivitas pelayanan umum dapat dilakukan berdasarkan pada tujuan penyediaan fasilitas pada lokasi pelayanan umum tersebut.

Berdasarkan hasil penilaian tingkat peminatan efektivitas pemanfaatan terminal terhadap 310 orang responden yang terdiri dari 15 orang dari stakeholder regulator, 122 orang operator (sopir) dan 173 orang stakeholder user (penumpang), maka diperoleh bahwa fasilitas dan manajemen terminal merupakan kriteria efektivitas pemanfaatan terminal yang memiliki bobot tingkat terbesar yaitu $39,97 \%$, yang kemudian pada kriteria aksesibilitas dengan prosentase bobot sebesar 33,06\%, keamanan $15,55 \%$ dan kenyamanan sebesar $11,42 \%$.

Hasil observasi dan survey di lapangan terhadap kondisi, ketersediaan, dan kecukupan atas penyediaan fasilitas dan manajemen dalam terminal belum sepenuhnya memenuhi standar minimal penyelenggaraan terminal tipe $\mathrm{C}$ sebagaimana telah diatur dalam Peraturan Menteri Perhubungan Republik Indonesia Nomor PM 40 Tahun 2015 tentang Standar pelayananan penyelenggaran terminal penumpang angkutan jalan seperti tidak tersedianya fasilitas yang menunjang keselamatan, keamanan, kenyamanan pengguna terminal antara lain: petunjuk dan jalur evakuasi saat terjadi bencana kebakaran dalam terminal, alat pemadam kebakaran, fasilitas, informasi dan petugas kesehatan, tidak ada petugas keamanan, toilet yang jumlah dan luasnya kurang dan tidak berfungsi, dan tidak tersedianya ruang makan dan termasuk ruang ibu menyusui serta tidak adanya sistem kegiatan dalam terminal, sedangkan aspek aksesbilitas yang merupakan penggabungan/pengkombinasian sistem tata guna lahan secara geografis dengan sistem jaringan transportasi yang menghubungkannya, kemudahan pengguna jasa (masyarakat) dalam mengakses terminal dan wilayah pusat kegiatan yang mereka kehendaki dengan harga yang bisa diakses (tidak mahal). Aksesibilitas dari prasarana jalan meliputi ketersediaan dan kondisi prasarana jalan dari dan/atau ke terminal pada prinsipnya lancar, tidak terlihat adanya titik macet, kondisi jalan baik dan tidak terlihat jalanan yang rusak seperti berlubang dan lain-lain.

Sedangkan aksesibilitas ditinjau dari sistem pergerakan melalui moda transportasi, tata guna lahan dan jaringan trayek yang menghubungkan antar suatu wilayah sangat memprihatinkan karena tidak adanya trayek angkutan umum yang jelas, tetap dan teratur sehingga pergerakan kendaraan dan penumpang angkutan umum tidakmelalui terminal. Disamping itu, lokasi terminal yang tidak berada di pusat kegiatan wilayah (PKW) melainkan berada dikawasan pengembangan kegiatan lokal promosi (PKLp) yang sampai saat ini belum ada kegiatan pengembangan local di dalam dan/atau sekitar terminal.

Selanjutnya kriteria keamanan sejauh ini tidak menjadi persoalan bagi penumpang dan masyarakat pada umumnya, karena sejauh ini tingkat kejahatan kriminal (copet, penodong dll) di kabupaten pangkep khususnya daerah kec. bungoro dan sekitarnya sangat rendah. Meskipun demikian berdasarkan hasil observasi di lapangan terhadap letak dan kondisi terminal yang tidak berada ditengah-tengah pemukiman, kondisi sekitar terminal dengan hamparan sawah yang kemudian dengan fasilitas keamanan dalam terminal seperti pos keamanan yang terbatas dengan kondisi rusak, maka perlu ada perhatian dari pemerintah untuk segera dilakukan pembenahan agar bisa difungsikan. Sedangkan untuk kriteria kenyamanan, berdasarkan hasil observasi/survey di lapangan masih relative kurang nyaman meskipun beberapa fasilitas yang menunjang keyamanan dalam terminal tersedia. namun masih banyak fasilitas dalam terminal yang menunjang kenyamanan pengguna (sopir dan penumpang) belum tersedia dan/atau masih kurang seperti jumlah toilet yang hanya sebanyak 2 (unit) dengan kondisi tidak berfungsi dan berbau, sampah berserakan, ruang tunggu yang kurang, dan tidak dilengkapi fasilitas kenyamanan seperti 
dinding/tirai pelindung panas matahari/saat hujan.drainase,ruang terbuka hijau, tempat sampah pada prisipnya sudah baik

Dengan uraian tersebut di atas, maka alternatif arahan efektivitas pemanfaatan terminal penumpang di kabupaten pangkajene dan kepulauan adalah:

1. Perlunya perhatian dari pemerintah untuk pemenuhan penyediaan fasilitas terminal termasuk melakukan perbaikan terhadap fasilitas yang telah rusak sehingga dapat difungsikan.

2. Sesuai Peraturan Menteri Perhubungan Republik Indonesia Nomor PM 132 Tahun 2015 tentang Penyelenggaraan Terminal Penumpang Angkutan Jalan bahwa salah satu pertimbangan penetapan lokasi terminal adalah tingkat aksesibilitas pengguna jasa angkutan, kesesuaian lahan dengan RTRW dan kesesuaian dengan rencana pengembangan dan /atau pusat kegiatan.

Seiring dengan hal tersebut dan sesuaidengan penetapan kecamatan bungoro sebagai kawasan Pengembangan Kegiatan Lokal Promosi (PKLp) sebagaimana diatur dalam Peraturan Daerah Nomor 8 tahun 2012 tentang Rencana Tata Ruang dan Wilayah Kabupaten Pangkajene dan Kepulauan, maka diharapkan tumbuhnya aktivitas ekonomi dalam dan sekitar terminal melalui:

a) Menciptakan sistem kegiatan dalam terminal seperti pemanfaatan kios-kios.

b) Mengarahkan pengembangan pusat kegiatan baik kegiatan wilayah maupun lokaldi dalam dan/atau sekitar terminal tepatnya jalan terminal baru seperti kegiatan pusat kuliner, bandeng tanpa duri (batari) dan lain-lain yang dapat menarik dan membangkitkan orang mengakses terminal baik bagi penumpang angkutan umum (user) maupun masyarakat umum.

3. Untuk menciptakan keteraturan pergerakan kendaraan angkutan umum maka diperlukan regulasi yang mengatur sistem jaringan trayek yang jelas termasuk perlunya penyusunan dokumen tatanan transportasi lokal (tatralok).

\section{KESIMPULAN}

Berdasarkan hasil analisis peminatan stakeholder terhadap efektivitas pemanfaatan terminal penumpang di Kabupaten Pangkep dalam penelitian ini, ada beberapa hal yang dapat dijadikan kesimpulan antara lain:

1. Dari 310 jumlah responden yang terdiri dari 15 orang responden regulator (pemerintah), 122 orang responden operator (sopir) dan 173 orang responden user (penumpang) maka diperoleh bahwa fasilitas dan manajemen terminal memiliki tingkat peminatan responden yang paling tinggi sebanyak 148 orang dengan prosentase bobot sebesar 39,97\%, kemudian aksesibilitas sebanyak 134 orang dengan prosentase bobot sebesar 33,06\%, keamanan terminal sebanyak 21 orang dengan prosentase bobot sebesar $15,55 \%$ dan kenyamanan terminal sebanyak 7 orang dengan memiliki prosentase bobot paling rendah yakni sebesar $11,42 \%$.

2. Berdasarkan hasil analisis peminatan stakeholder dan hasil observasi kondisi eksisting terminal penumpang di Kabupaten Pangkep, maka dirumuskan alternatif arahan dalam rangka efektivitas pemanfaatan terminal yaitu perlunya pemenuhan penyediaan fasilitas, termasuk melakukan perbaikan terhadap fasilitas yang telah rusak sehingga dapat difungsikan. Disamping itu perlunya menciptakan sistem kegiatan dalam terminal seperti pemanfaatan kios-kios, mengarahkan pengembangan pusat kegiatan baik kegiatan wilayah maupun lokal di dalam dan/atau sekitar terminal tepatnya jalan terminal baru seperti kegiatan pusat kuliner, bandeng tanpa duri (batari) dan lain-lain yang dapat menarik dan membangkitkan orang mengakses terminal baik bagi penumpang angkutan umum (user) maupun masyarakat umum, serta perlu regulasi dan dokumen perencanaan yang mengatur sistem jaringan trayek yang jelas seperti dokumen tatanan transportasi lokal (tatralok).

\section{SARAN}

Terkait dengan judul penelitian analisis peminatan stakeholder terhadap efektivitas pemanfaatan terminal penumpang di kabupaten pangkajene dan kepulauan dengan keluaran berupa prioritas faktor-faktor dan alternative arahan efektivitas pemanfaatan terminal, maka 
terdapat beberapa hal yang menjadi pertimbangan oleh stakeholder agar terminal dapat dimanfaatkan dan berfungsi secara efektif antara lain:

1. Perlunya perhatian dari pemerintah daerah untuk pemenuhan kecukupan, penyediaan fasilitas terminal termasuk melakukan perbaikan terhadap fasilitas yang telah rusak sehingga dapat difungsikan.

2. Agar pemerintah daerah dapat mendorong tumbuhnya aktivitas ekonomi dalam dan sekitar terminal melalui:

a) Menciptakan sistem kegiatan dalam terminal seperti pemanfaatan kios-kios.

b) Mengarahkan pengembangan pusat kegiatan baik kegiatan wilayah maupun lokal di dalam dan/atau sekitar terminal tepatnya jalan terminal baru seperti kegiatan pusat kuliner, bandeng tanpa duri (batari) dan lain-lain yang dapat menarik dan membangkitkan orang mengakses terminal baik bagi penumpang angkutan umum (user) maupun masyarakat umum.

3. Agar pemerintah daerah sebagai regulator menyusun dan menetapkan regulasi yang dapat menciptakan keteraturan pergerakan kendaraan angkutan umum penumpangseperti penetapan jaringan trayek yang jelas dan teratur, serta menyusun dokumen tatanan transportasi lokal (tatralok).

4. Agar masyarakat pada umumnya dapat memahami dan mendukung arah kebijakan pemerintah dalam upaya efektivitas pemanfaatan terminal penumpang di kabupaten pangkep khususnya terminal pangkajene (ex.bungoro)

\section{DAFTAR PUSTAKA}

Anonim, 1992; Undang-Undang No.14 Tahun 1992 tentang Lalu- Lintas dan Angkutan Jalan, Jakarta.

Anonim, 2009; Undang-Undang No.22 Tahun 2009 tentang Lalu-Lintas dan Angkutan Jalan, Jakarta.

Anonim, 2015; Peraturan Menteri Perhubungan RI. Nomor PM 40 Tahun 2015 tentang Standar Pelayanan Penyelenggaraan Terminal Penumpang Angkutan Jalan, Berita Negara Republik Indonesia Tahun 2015 Nomor 306, Jakarta.

Anonim, 2015; Peraturan Menteri Perhubungan RI. Nomor PM 132 Tahun 2015 tentang Penyelenggaraan Terminal Penumpang Angkutan Jalan, Berita Negara Republik Indonesia Tahun 2015 Nomor 1295, Jakarta.

Anonim, 1995; Keputusan Menteri Perhubungan No.31 Tahun 1995 tentang Terminal Transportasi Jalan, Jakarta.

Anonim, 2002; Teknis Penyelenggaraan Angkutan Penumpang Umum di Wilayah Perkotaan Dalam Trayek Tetap dan Teratur, Direktorat Jenderal Perhubungan Darat, Jakarta.

Anonim "Direktorat Bina Sistem Prasarana, Pedoman Teknik Pembangunan Terminal Angkutan Jalan Raya Dalam Kota dan Antar Kota.

Abubakar, I., 1995; Menuju Tertib Lalu lintas, Departemen Perhubungan Direktorat Jenderal Perhubungan Darat, Jakarta.

Morlock, Edward.K. 1978; Pengantar Teknik dan Perencanaan Transportasi, Terjemahan. Jakarta; Penerbit Erlangga. 
Tamin Ofyar. Z. 1997; Perencanaan \& Pemodelan Transportasi, Bandung; Penerbit ITB.205,204

Lambang Basri Said, Abdul Kadir Salim, 2008; Dasar-dasar Rekayasa dan Manajemen Transportasi, PT. Umitoha Ukhuwah Grafika Makassar.

Hasan Husni, 2011; Kamus Populer Transportasi dan Logistik, Sekolah Tinggi Manajemen Transportasi Trisakti, Jakarta.

Purba Djamahaen, 2008; Analisis Faktor-faktor yang mempengaruhi Efektivitas Fungsi Terminal Sarantama (Studi Kasus Terminal Sarantama kota Pematang Siantar), Thesis, Fakultas Pasca Sarjana Universitas Sumatera Utara Medan.

Muradi Dadi, 2005; Pemanfaatan Terminal Angkutan Regional terkait Dengan Kebijakan Pengembangan Wilayah Kota Pangkal Pinang, Thesis, Fakultas Pasca Sarjana Perencanaan Pembangunan Wilayah dan Kota Univeritas Diponegoro Semarang.

Parapat, Renward 2006; Analisis Prioritas Faktor-Faktor Yang Mempengaruhi Efektifitas Terminal Amplas, Thesis, Fakultas Pasca Sarjana Teknik Arsitektur, Universitas Sumatera Utara, Medan.

Rudhy Akhwady, 2006; Studi Rencana Tata Ruang Kawasan Pesisir Dengan Metoda Analytic Hierarchy Process (AHP) Kabupaten Pasuruan, Thesis, Fakultas Pasca Sarjana Teknik Manajemen Pantai Institut Teknologi Surabaya.

Ekowati Yuli Widyaningsih, 2012; Penerapan Analisis Hirarki Proses (AHP) dalam Penentuan Formula Alokasi Dana Desa di Kabupaten Seragen, Thesis, Fakultas Pasca Sarjana Ekonomi dan Studi Pembangunan Universitas Sebelas Maret, Surakarta.

Saaty, T.L., 1993; Pengambilan Keputusan Bagi Para Pemimpin, P.T. Pustaka Binaman Pressindo, Jakarta.

Guillermo A. Mendoza, Phil Macoun, dkk. 1990; Panduan untuk menerapkan Analisis Multi Kriteria Dalam Menilai Kriteria dan Indikator, Jakarta; Center for International Forestry Research (CIFOR)

Fidel Miro. 1997; Sistem Transportasi Kota, Bandung; Penerbit Tarsito.

Idwan Santoso. 1996, Perencanaan Prasarana Angkutan Umum, Bandung; Pusat Studi \& Komunikasi Institut Teknologi Bandung.

Marimin. 2004; Teknik dan Aplikasi Pengambilan Keputusan Kriteria Majemuk, Jakarta; Penerbit PT Grasindo.

M. Iqbal Hasan. 1992; Pokok-pokok Materi Metodelogi Penelitian dan Aplikasinya, Jakarta; Penerbit Ghalia Indonesia.

Singarimbun Masri. 1989; Metode Penelitian Survei, LP3S Jakarta.

Sudjana. 1992; Metode Statistik, Bandung; Penerbit Tarsito.

Soekidjo Notoatmojo, 2002; Metodologi Penelitian Cet. Ke-2, Rineka Cipta, Jakarta.

Bakhtiar Anang, 2014; Kajian Efektivitas Operasional Terminal Madyopuro Malang, Jurnal Rekayasa Sipil, No. 1, Volume 8. 
Musdalifah, M.Isya, M.Saleh Sofyan, 2015; Faktor-faktor ketidakefektifan Fungsi Terminal Terpadu Pata Ilalang Takengon, Jurnal Teknik Sipil, No. 2, Volume 4.

Sagi, F.N., et.al, 2015; Kajian Faktor-faktor Penyebab Ketidakefektifan Kinerja Terminal Bus Haumeni Kota Soe Kabupaten Timor Tengah Selatan, Jurnal Teknik Sipil, No. 2, Volume IV.

Joesoef, J. R., 2002; Analityc Hierarchy Process (AHP) dan Penentuan Produk Kinerja, Jurnal Bisnis dan Ekonomi, Volume 6, hal 30-38. Ik industry, no. 1, vol. 2, hal 1-12.

Iryanto. 2004; Perbandingan berpasangan dalam proses analitik Hirarki, no.2, Volume 5, hal. 9-13.

Alonso, J.A., dan Lamata, M.T., 2006; Consistency In The Analytic Hierarchy Process; A New Approach, International Journal of Uncertainty, no 4, volume 14, hal.445-459.

A. Practical Method For Improving Consistency of Judgment Matrix In The AHP, Journal of System Science and Complexitym no.2, vol. 17, hal 169-175.

Roso Violeta, Brnjac Nikolina, Abramovic Borna. 2015; Inland Intermodal Terminals Location Criteria Evaluation: The Case of Croatia, International Journal of Transportation, No. 4 Vol. 54 hal. 496-515

S. Fard Nasser, Gunawan Indra. 2005; Terminal Realibilty improvement of Shuffle Exchange, International Journal of realibity, quality and safety engineering no.01 Vo. 12 hal. 5160

Mohd. Arip Mohd Sabri, Zainol Halmi, Rashid Khushairi, Noor Mohid Mohamed, A. Tambi Abdul malik. 2018; Perencanaan Terminal Angkutan Antarmoda di Malaysia, International Journal of Academic Research in Business \& Social Sciences No.11 Vol. 8 . 